\title{
Sciendo
}

\section{The Asian Experience for Europe: New Perspectives ${ }^{1}$}

At the end of the second decade of the 21st century, global disruption has become normalised, be it represented by the long shadow cast by $9 / 11$, the USA, Russia, China, Brexit, or climate change. The individual articles in this Special Issue present a diverse array of analyses and topics: what binds them together, however, is the perspective of change. The twentieth-century certainties are no longer adequate explanations as the evolving mosaic of Asia-Pacific relations continues to surprise even the most well-informed commentators. Contemporary developments in China, North Korea, and Japan collectively present a new international relations subsystem of issues that challenge the existing multilateral and strategic context of the Asia-Pacific. Additionally, the different regionalisms as expressed by the Belt and Road Initiative (BRI) and the Asia-Europe Meeting (ASEM) process emphasise the intercontinental connectivity of Asia-Pacific relations, while generating plenty of serious discussions on the topic in the European Union (EU).

The Special Issue falls into two parts: an examination of regional approaches (BRI and ASEM) and country-specific case studies (Singapore, Japan, North Korea, and Taiwan) and how these have been affected by the rise of China. The diversity of the contributions perfectly matches the kaleidoscopic patchwork that represents the Asia-Pacific and articulates the important juxtaposition of EU solidarity with the more pragmatic alliances that help in shaping the regionASEM, Association of Southeast Asian Nations ASEAN, as well as traditional bilateralism.

This collection is neatly bookended by two broadly regional-based approaches. First, Doidge (p. 6) considers ASEM's influence of "identity building, norm diffusion and dialogue without preconceptions". Resilience of interregionalism has perhaps surprised many due its modest substantive outcomes; however, the fact that the framework has doubled in size illustrates that there is a mature appreciation of its dialogue-based value and normative cooperation. Second, the concluding articles by Leandro and Galan (pp. 122-151; 152-181) question traditional assumptions concerning borders in the light of the BRI and consider

1 This research has received funding from the European Union's Horizon 2020 research and innovation programme under the Marie Skłodowska-Curie grant agreement No. 734712. 
de-bordering, re-bordering, and co-bordering as new concepts experienced within a European space as well as promoted by the BRI connectivity. Despite integration initiatives in Europe and Asia, borders remain paradoxically resilient. Additionally, the effect of the BRI on the structure of international financial governance is raised and the emergence of new regional players such as the Asian Infrastructure Investment Bank (AIIB) that are reshaping Asia's global role are noted, with China's role characterised (albeit contested) as a Chinese Marshall Plan. What is uncontested, however, is the impact this new financial institutionalism has already had on the Bretton Woods Western influence on Asia's economies.

The five articles sandwiched in between present a series of valuable countryfocused analyses that are rich in their local knowledge and help to avoid gross generalisations about Asia, let alone those mythical "Asian values". For example, Chiu (pp. 61-73) offers a discussion on the phenomenon of city-networks in the context of addressing global environmental issues. She examines the case of Tokyo, arguing that cities are important sites of policy experimentation and innovation; evidently, the case of Tokyo demonstrates the potential of crosscountry policy diffusion at the city-to-city level. Lay Hwee Yeo (pp. 20-39) approaches the topic from the perspective of a small Asian country that uses regional platforms to enhance its security, influence and relevance. ASEAN, APEC, ARF, and most recently the AEC were premised on open regionalism that was outward-looking and less constrained by internal cooperation. The risk in such a loose regionalism is, of course, a lack of leadership as each Asian partner remains hesitant about the underlying interests of competing economies - be they China, Japan, or the USA. While the case of Japan echoes to some degree the strategic approach of Singapore, the article by Koga Koga (pp. 40-60) reminds us of the geo-political realities of realpolitik. Japan's dualtrack diplomacy has prioritised economic strength over military prowess and evolved into a broader multilateral concept. Strikingly, the inherent threat to Japan's regional credibility has emanated directly from a single power-the USA.

In contrast, Ting (pp. 74-96) considers the evolving complexities consequential to China's rise, particularly in relation to Sino-Japanese relations and the resolution of North Korean denuclearisation issue. The relative weakness of Chinese soft power is placed into stark relief $v i s-\grave{a}$-vis the normative influence of the EU in the region; the USA's pivot and rebalancing towards Asia also constrains China's hard power in the absence of any effective multilateral regional security architecture. Despite the rise of China, this has yet to result in a fundamental geo-political transformation in Northeast Asia-although the 
trajectory is becoming increasingly apparent. Wong's (pp. 97-121) article on Taiwan also echoes the interlinked relationship of the USA and China in its historical review of this 70-year long regional issue. It underlines the analytical importance of adopting a long-term time horizon - in the case of Taiwan, the centenary of the founding of the CCP is suggested as the pivotal moment for change.

The range of topics covered in this Special Issue serve to remind everyone of the global scope and prescience of Europe's policy domains and how these remain important in shaping Asia's future in tandem with changing American and Chinese ambitions. As this volume attests, there are new and emerging players who aspire to be the dominant architects reshaping international relations in the 21 st century: the EU's position as a champion of interregionalism is under threat. The Asian experience was relatively slow to emerge and somewhat neglected by Western scholars of the last century. This timely volume helps to correct this imbalance. The first steps for this Special Issue to appear were made in the framework of the joint project run by Tallinn University of Technology, Tallinn University, the University of Tartu, 'Founding a Competence Centre of Asian Studies and Developing Research' project (AUKLASTA). The final stage of this academic initiative was completed with the project 'Institutions for Knowledge Intensive Development: Economic and Regulatory Aspects in South-East Asian Transition Economies', within European Union's Horizon 2020 research and innovation programme under the Marie Skłodowska-Curie grant agreement No. 734712.

DSocSc candidate Vlad Vernygora, University of Lapland, Finland, and Tallinn University of Technology, Estonia

Professor Martin Holland, University of Canterbury, New Zealand

Professor Natalia Chaban, University of Canterbury, New Zealand

Professor Tanel Kerikmäe, Tallinn University of Technology, Estonia 